\title{
EMPODERAR: NUEVO CONCEPTO DE LIDERAZGO PARA EL ADMINISTRADOR EDUCATIVO
}

Luis Enrique González Salazar

Resumen: En este artículo se realiza un análisis de las dos directrices enviadas por el Dr. Claudio Gutierrez cuando fue Ministro de Educación, en las que se "empoderaba" a las direcciones regionales de educación y se ponía en práctica el principio de subsidiaridad, para establecer una nueva manera de relacionar las direcciones regionales con las oficinas centrales del Ministerio y éstas con las Instituciones Educativas. Se enfatiza en el potencial de este concepto de liderazgo con el objeto de analizar el estado actual del proceso de "empoderamiento" en la Dirección Regional de Alajuela, visto este como un continuo entre la autonomía y el control en los estilos de liderazgo practicado por los directores cinco del circuito 01.

\section{Introducción}

En julio de 1998, siendo Ministro de Educación el Dr. Claudio Gutiérrez Carranza, se "empoderó" a las Regiones Educativas como un recurso para aumentar la calidad y cantidad de educación ofrecida a la población de Costa Rica.

Con el potencial que ofrece esta iniciativa de concesión de poder a los administradores educativos, se pretendía motivar para que con ayuda de colaboradores comprometidos, ingresara la organización educativa con buen tino al siglo XXI.

El "empoderamiento" es una estrategia que necesita administradores educativos capaces de distribuir su poder, capaces de facultar a sus recursos humanos.

Es un medio por el que se procura desarrollar administradores de organizaciones educativas a quienes se les pueda conferir poder para convertirse en protagonistas en la toma de decisiones de índole técnico administrativas y en aspectos tan puntuales como didáctica para cada asignatura, destrezas en el manejo grupal, psicopedagogía del niño y del adolescente, desarrollo de la motivación y delegación efectiva de funciones.

Así al administrador educativo se le confiere el poder de decidir el uso que le debe dar a los servicios de apoyo que presta el Ministerio de Educación, a pedido y por iniciativa de éstos (MEP, 1998). 
Este artículo pretende demostrar que pese a todo lo que se dice, el empoderamiento, como concepto de liderazgo para implementar programas de cambio en las organizaciones educativas, sigue siendo más que todo una ilusión. El mando y el control siguen siendo lo típico y el mayor poder de decisión dentro y fuera del aula, lo atípico (González, 1999).

Para ello, el artículo presenta la siguiente estructura: potencial del concepto, poder de compromiso, unidad y lucha de poder, ilusiones de poder, autonomía y control e impugnar el poder. Cierra el artículo una conclusión general y una serie de recomendaciones con las que se pretende aportar criterios sobre la concesión de más poder de decisión, dentro y fuera del aula, al personal en las organizaciones educativas.

\section{Potencial del concepto}

En vista del potencial que ofrece este concepto de liderazgo, que tiene sus orígenes en la destrucción del muro de Berlín, se fundamenta en las iniciativas de la calidad total, la administración estratégica y se remonta a mediados de los años 80, es extraño que el empoderamiento no haya recibido mayor atención por parte de los administradores de la educación (González, 1999).

Sería contradictorio que un directivo no quisiera personal docente y docente administrativo comprometido a colaborar con la institución y que ésta ingrese sinergiada al siglo XXI.

Los directivos, según lo manifestaron al investigador en conversaciones informales, aceptan gustosos la responsabilidad de desarrollar colaboradores a quienes se les pueda conferir mayor poder de decisión, en el tanto y cuanto son parte de las facultades otorgadas a los docentes por el Consejo Superior de Educación.

Sin embargo, no todo ello es suficiente para facultar. La observación, investigación y experiencia de más de quince años en labores docentes y administrativo docentes del suscrito, le indican que los mejores resultados en materia de delegación de poder de decisión al personal, se logran cuando se aplica rigurosamente el Manual Descriptivo de la Clase de Puestos Docentes del Servicio Civil Docente de la Dirección General de Servicio Civil, como claro referente para la Gestión Administrativa (DGSC, 1998).

Las razones de esto siguen siendo un enigma.

Los planes, programas y proyectos de cambio organizacional empleados por los administradores educativos, abundan en contradicciones internas que frenan más que estimulan la motivación y el compromiso en el personal docente y docente administrativo (González, 1999).

Son los mismos administradores educativos, con su estilo de dirección, los que se encargan de menoscabar sutilmente la delegación de poder de decisión al personal.

A los directivos les parece excelente delegar funciones y poder en el personal, pero el modelo que mejor conocen y en el que más confían es en el de mando y control.

Por su parte, el personal docente y docente administrativo tiende a ser ambivalente en cuanto a la delegación de funciones: es magnífico siempre y cuando, no tengan que responder personalmente y la responsabilidad siga siendo del administrador educativo.

Así pues, pese a la retórica de la delegación de responsabilidad y autoridad en la directriz de setiembre del 98 en el Boletín de Supervisión Nacional, el empoderamiento es hoy día como el atuendo del emperador: se alaba con entusiasmo en público pero al interior de las organizaciones educativas no se puede ver.

No se ha producido ninguna transformación ni metamorfosis en el personal docente y administrativo, pese a las facultades otorgadas por el Consejo Superior de Educación (González, 1999).

\section{Poder de compromiso}

A manera de explicación tentativa del fenómeno de la delegación efectiva de poder 
al personal, y así se desprende del informe de investigación, del que este artículo es producto, se puede afirmar, sin ser temerario, que no se ha producido ningún cambio significativo en la distribución del poder de decisión por falta de compromiso, tanto de los directivos como del resto del personal en las organizaciones educativas (González, 1999).

$\mathrm{Ha}$ de pensarse en el compromiso como una idea esencial que implica un convenio, acuerdo y obligación contractual para la producción de pensamiento educativo relacionado con el proceso de facultar.

Una rica y generadora idea de pensamiento pedagógico que permite poner en marcha cualquier innovación educativa. Un enfoque del compromiso como insumo para liberar el potencial creativo de los recursos humanos con que cuentan las organizaciones educativas.

Partiendo de lo anterior, podría pensarse que al menos hay dos maneras antagónicas y complementarias de comprometer al personal docente y docente administrativo: compromiso externo y compromiso interno.

Compromiso externo es cuando se logra, de manera contractual, que los colaboradores cumplan con sus deberes. Es lo que obtiene una organización educativa cuando el personal ejerce poco control sobre sus funciones, lo cual significa que a menor poder subsidiado, menor compromiso sentirán los docentes con su trabajo.

Por ejemplo, cuando el administrador educativo define por sí solo las condiciones de trabajo del personal, casi con seguridad, estos tendrán un compromiso externo.

Es externo porque lo único que puede hacer el personal es cumplir con lo que se espera de ellos, pero no se sentirán con autoridad y responsabilidad por la forma en que se defina en sí la labor docente y docente administrativa.

Si el administrador educativo quiere que el personal a su cargo asuma mayor responsabilidad y autoridad por su propio trabajo dentro de la organización, debe fomentar el compromiso interno.
Por definición, el compromiso interno proviene del interior, de la motivación para comprometerse con un plan, programa o proyecto. Es participación y se relaciona directamente con valores como equidad, franqueza, solidaridad, honestidad y confianza, que son los pilares del empoderamiento (González, 1999).

Mientras más busque el administrador educativo un compromiso interno entre sus colaboradores, más tendrá que convencer e influir en estos para y por incluirlos en la definición de los objetivos institucionales, las estrategias y planes para alcanzarlos y la fijación de metas progresivas (Arroyo Valenciano, 1999).

Cabe preguntarse si, para que exista empoderamiento todo el personal docente y docente administrativo debe participar.

En apariencia, la respuesta es "sí"; no obstante, en esencia, es poco realista que el administrador educativo de direcciones cinco, permita a más de treinta y cinco colaboradores participar en un proyecto de auto gestión y cogestión directiva, que es la visión del proceso de facultar.

Por lo tanto, la plausibilidad del compromiso interno en una organización educativa es, sin duda, limitado.

Además, el grado de participación del personal en los planes, programas y proyectos, varía de acuerdo con los intereses y motivaciones de cada cual.

La delegación de funciones al personal, la distribución del poder de decisión, es una meta a la que el directivo se aproxima, pero nunca se alcanza del todo.

De hecho, coexisten diversos niveles de delegación de funciones y esto permite que se realicen las tareas pedagógicas y correlacionales con éstas.

Así pues, lo primero que tiene que aprender el administrador educativo es el manejo de límites en asuntos del compromiso interno.

Por ejemplo, no puede pregonar el compromiso interno al tiempo que exige un compromiso externo entre sus colaboradores. 
No debe poner en entredicho su credibilidad en asuntos tan delicados del comportamiento humano.

Es claro que si el compromiso interno es lo que produce el tipo de resultados que las directrices supracitadas pregonan, entonces debe ser realista y sensato el directivo en sus demandas de dicho compromiso.

El problema se ahonda porque con el estilo de liderazgo curricular practicado por los directivos consultados, disuaden éstos al personal de asumir una responsabilidad más allá de lo puramente contractual (González, 1999).

\section{Unidad y lucha de poder}

El gran programa de cambios que se proponía en la relación entre las Direcciones Regionales de Educación, las oficinas centrales del Ministerio Educación Pública y los centros educativos, contiene una gran cantidad de contradicciones internas.

De acuerdo con las directrices ministeriales, le corresponde a los directores de las instituciones educativas ser los protagonistas en la toma de decisiones de índole administrativa y de la dirección técnica.

Para ello, por ejemplo, la Dirección Regional de Educación de Alajuela, emanó un conjunto de políticas y creó instrumentos para recolectar información útil que le permitiera a las instituciones educativas elaborar un plan de capacitación, basado en las reales necesidades de los docentes del centro educativo.

El objetivo era organizar un plan de capacitación para cumplirse en un período de tres años.

El instrumento no fue aplicado por algunos directores, la información no se recolectó y el plan quedó en el olvido, entre otras causas por falta de compromiso interno de éstos.

No se logró diagnosticar las debilidades y fortalezas del recurso humano de cada una de las direcciones cinco del circuito 01. El plan cayó en el olvido y nunca se clarificaron y fortalecieron los aspectos débiles (González, 1999).
El programa y las políticas no fueron ejecutadas correctamente y por lo tanto, no fomentaron el comportamiento que se supone debían inspirar a los directores y docentes.

Es más, muchos administradores educativos no se enteraron de la existencia de planes, programas y proyectos para facultar, y menos aún, de la existencia de un instrumento que detecta necesidades de capacitación para empoderar a las instituciones educativas.

Las contradicciones en cuanto a comunicación y seguimiento nunca se llevaron a la superficie ni fueron abordadas, por lo que, se convirtieron en la más destructiva fuerza que frenó el desarrollo del empoderamiento.

El programa terminó por crear confusión y no pudo conferir poder ni ser liberador y los actores involucrados terminaron distanciándose discretamente de lo emanado en las directrices del señor Ministro y nadie asumió una responsabilidad personal al respecto.

De esta manera, el espacio y el tiempo que se pretendía abrir para clarificar y fortalecer las partes débiles de los recursos humanos de cada institución educativa nunca se creó y lo que se quería erradicar más bien se reforzó y fortaleció (González, 1999).

El empoderamiento, por ineficiencia y procacidad de las autoridades, sigue siendo en el circuito 01 de la Dirección Regional de Educación de Alajuela, más que todo un espejismo.

\section{Ilusión de poder}

Infiere el investigador de las conversaciones informales sostenidas con los directores cinco del circuito 01 de la DREA que éstos trabajan contra el empoderamiento porque no siempre parecen querer lo que dicen que necesitan.

Estas conversaciones pusieron claramente de relieve la ambivalencia de los directores frente al compromiso interno y el empoderamiento.

Un primer director comentó que el ordenamiento del cargo docente, ajustado a las responsabilidades, tareas y deberes, hace que las divergencias sean pequeñas y los límites

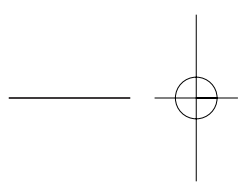


de autoridad estén bien especificados. Agregó que siempre y cuando respeten los límites, está dispuesto a conceder poder. Otro comentó que a muchos docentes les es difícil entender qué significa el hecho de que los procesos educativos deben estar bajo control.

Cabe preguntarse lo siguiente: ¿Cómo puede haber empoderamiento cuando los requerimientos del cargo están predeterminados en el Manual Descriptivo de Clases de Puestos Docentes y los procesos educativos controlados por la dirección?

En este entorno, la concesión de poder es una mera ilusión. No es un entorno en el que los docentes puedan aspirar a regirse ellos mismos. Por el contrario, este entorno obliga al personal docente y docente administrativo a volverse más externamente motivados.

El administrador educativo tiene, hoy día, recursos generosos a su disposición para garantizar el cumplimento de los deberes por parte del personal y una gran cantidad de instrumentos para supervisar con frecuencia los avances en el proceso de enseñanza aprendizaje.

Todo lo cual le permite reforzar los factores de control de arriba hacia abajo en el modelo de compromiso externo que, como se ha indicado, aniquila el sentimiento de responsabilidad interna y empoderamiento personal.

Así pues, parece que los directores no quieren realmente personal docente y docente administrativo con más poder de decisión dentro y fuera del aula.

Es decir, no parecen querer lo que dicen que se necesita para el cambio organizacional.

\section{Autonomía y control del poder}

El compromiso externo, y se dice con conocimiento de naturaleza fenoménica por parte del investigador, acumulado, haciendo uso del método etnográfico de la observación participante, en instituciones educativas del circuito 01 de la DREA, se ha constituido en un mecanismo de adaptación y supervivencia en casi todos los entornos laborales de las instituciones educativas del circuito 01 .
Esto se aprecia muy bien cuando los docentes manifiestan en conversaciones informales, que han aprendido a definir el desempeño docente como hacer únicamente lo que les exige el director. Han aprendido a vivir la vida laboral de acuerdo con las reglas del compromiso externo, a obedecer y a no tomar ninguna iniciativa (González, 1999).

Y como la exposición prolongada a un compromiso externo hace muy poco probable el compromiso interno, tanto educadores como administradores educativos no han aprendido ha empoderarse. Y es que el sentido de empoderamiento no es innato, se tiene que aprender, desarrollar y perfeccionar.

Por esto, entre otras razones, es que se sostiene que el empoderamiento es un devarío en las organizaciones educativas, por lo menos, en este momento.

La pregunta, entonces, es ¿cómo se produce el compromiso interno?

Conversando informalmente con los docentes del circuito, deduce el investigador que éstos no acogen con entusiasmo la idea del empoderamiento porque les significa demasiado trabajo, y han aprendido a sobrevivir con base en el compromiso externo.

Es decir, los educadores y los directores parecen empeñados en resolver un conflicto con un enemigo imaginario.

El administrador educativo dice que quiere docentes que participen más; los educadores dicen que quieren participar más. Sin embargo, es difícil saber qué quiere cada actor. Podría tratarse tan solo de una comedia.

Los docentes procuran tener más autonomía, los directores dicen estar de acuerdo, pero tratando de mantener el control a través de mecanismos de supervisión, y los docentes ven en este modelo de mando y control, la negativa de la dirección a que se impugne su poder.

Así pues, queda de lo propuesto en las directrices ministeriales, una batalla entre autonomía y control; y entre tanto, el empoderamiento sigue siendo más que todo una quimera, un espejismo, una utopía en las instituciones educativas del circuito 01 de la DREA. 


\section{Impugnar el poder}

Atrapado en medio de la batalla entre autonomía y control, el administrador educativo afronta una difícil tarea si quiere conferir más poder de decisión en su organización.

Una manera que tiene el directivo para equilibrar este juego de poder, es, estudiar y aplicar el enfoque moderno de la administración por valores y su propuesta del compromiso con una misión y unos valores compartidos como medio para lograr éxito organizacional (Blanchard, 1997).

En teoría, el empoderamiento debería facilitarle al administrador de la educación el cumplimiento de la misión, visión y valores institucionales.

Pero, como se ha dicho anteriormente, el enfoque de la distribución del poder ha ingresado al dominio de lo que se juzga políticamente correcto, es decir, una propuesta más utópica que real, dado que, cada vez que el personal docente y docente administrativo tiene problemas, piden ayuda al directivo y el director les dice qué tienen que hacer. No practica el personal el tan pregonado mayor poder de decisión.

Así es como se realiza la mayoría del trabajo institucional, lo cual no tiene nada de malo, salvo que va en contra de la teoría del empoderamiento.

Todo el enfoque se convierte de esta manera en una ilusión y coloca al administrador educativo entre la espada y la pared.

Por ello, se afirma que el empoderamiento implica un cambio de mentalidad que empieza cuando el directivo cambia su estilo de liderazgo y permite que se impugne su poder de decisión (González, 1999).

\section{Conclusión}

Pese a la retórica que rodea al programa de transformaciones y grandes cambios entre las instituciones educativas, las direcciones regionales y la oficinas centrales del Ministerio de Educación, pregonado en las dos di- rectrices ministeriales comentadas, y las facultades a los docentes otorgadas por el Consejo Superior de Educación, la realidad es que los administradores educativos no han encontrado la fórmula para hacer funcionar el empoderamiento en las instituciones educativas.

Como se ha comentado anteriormente, las razones siguen siendo un enigma.

A los administradores educativos les compete parte de la responsabilidad por menoscabar la participación interna en sus colaboradores, pero, la verdad es que el Ministerio de Educación y sus representantes, todavía no han puesto en marcha programas de cambio que creen altos niveles de compromiso interno y empoderamiento en las direcciones regionales y éstas menos aún en las instituciones educativas.

Con el fin de colaborar en el proceso de la concesión de más poder de decisión dentro y fuera del aula, el suscrito dará algunas recomendaciones sobre el enigma, que pueden ayudar a los administradores educativos a reflexionar sobre el empoderamiento con un alta grado de prudencia.

- $\quad$ Reconozca que todas las instituciones educativas tienen a la vez controles de arriba abajo y aún así, puede conferir poder a sus colaboradores y que en esta concesión es inevitable que surjan contradicciones en su actitud y debe aprender a manejarlas. Además, cuando se vuelvan aparentes exteriorícelas delante de sus colaboradores para no crear una brecha de credibilidad en cuanto a sus esenciales intenciones.

- Cuando emprenda un programa de cambio, esté claro que su intención ha de ser expandir el compromiso interno. Es decir, asegúrese de que lo que está propugnando no contradiga lo que sucede en la realidad.

- Entienda usted que la concesión de poder tiene sus límites. Sepa cuanto puede delegar y cuánto puede lograr con esto. Tenga en cuenta que no se trata de una panacea. Una vez concedido 
el poder, no lo utilice mal. Especifique los límites probables en el uso del poder y la cogestión.

- Comprenda que en toda institución educativa coexisten el compromiso externo y el compromiso interno, pero la forma en que ambos se puedan equilibrar resulta crucial para el éxito o fracaso en la distribución del poder. Distinga con sensatez, entre funciones que requieren un compromiso interno, y funciones que no lo requieren.

- $\quad$ Cree condiciones laborales que fomentes el empoderamiento en la institución. Una manera de ayudar al personal a dejar el compromiso externo, es instando a examinar su comportamiento. Sea sincero, promueva la autonomía y refuerce el compromiso con recompensas.

- En cuanto a las relaciones humanas considere factores como el estado de ánimo, la satisfacción, el compromiso y especialmente el desempeño académico de estudiantes y educadores para promover una sensación de empoderamiento.

- $\quad$ Sirva usted, estimado colega, de catalizador del personal para que entiendan el valor de la palabra compromiso como convenio, acuerdo y obligación contraída para que nadie en la organización se engañe con deliberada intención acerca de su real y verdadera intención.

- Finalmente, sea realista sobre cómo obtener y utilizar su poder. Es decir, en el espacio y tiempo de su gestión administrativa, confiera poder parte del tiempo y en espacios específicos a todos sus colaboradores. A algunos miembros del personal confiera poder todo el tiempo. Pero, no confiera poder a todo el personal, todo el tiempo y el espacio en que se circunscribe su gestión. Nadie debe esperar que usted distribuya su poder todo el tiempo.

\section{Referencias bibliográficas}

Arroyo Valenciano, Juan Antonio. Administración Estratégica en las Organizaciones Educativas. San José: UCR, 1999.

Blanchard, Ken. Empowerment. Colombia: Editorial Norma, 1996.

Blanchard, Ken y O'Connors, M. Administración por Valores. Colombia: Editorial Norma, 1997.

Ministerio de Educación Pública. Directrices $N^{\circ} 1$ y $N^{\circ} 2$. Boletín de Supervisión Nacional. Año XVIII, setiembre 98, No 81.

Dirección Regional Educación Alajuela. Departamento Desarrollo Educativo. Instructivo para Diagnosticar Necesidades de Asesoramiento en las Instituciones de la DREA. Alajuela: DREA, 1999.

Dirección General de Servicio Civil. Manual Descriptivo de Clases de Puestos Docentes. San José: DGSC, 1998.

González Salazar, Luis Enrique. Influencia del Empoderamiento a los Docentes en la Supervisión Educativa. Informe de Investigación para optar por el grado de Magister en Educación, San José: UCR, 1999. 